\title{
Assessing Teachers' Knowledge of Mathematical Modeling: Results from an Initial Scale Development
}

\author{
Reuben S. Asempapa \\ Penn State Harrisburg, Middletown, PA, USA
}

This pilot study underscores the claim that teachers' mathematical content knowledge plays a significant role in their teaching profession. Specifically, this article reports on the initial development of a scale to empirically measure teachers' knowledge of the nature of mathematical modeling from a Midwestern school district $(n=71)$. The phases used in this initial scale development included item generation, experts' reviews, item analysis, and factor analysis. Reliability, factor analysis, and scaling work confirmed the scale is a reliable and valid measure to assess teachers' knowledge of the nature of mathematical modeling. Findings from this study contribute to an important discussion about the need for further research and the development of quantitative tools for supporting instruction of mathematical modeling. Implications for teacher preparation and professional development are also discussed.

Keywords: mathematical modeling, modeling process, scale development, teacher knowledge, teacher education

Researchers and standards emphasize the need to address the skills and understanding of mathematical modeling in the teaching and learning of mathematics (Blum, 2015; Blum \& Borromeo Ferri, 2009; Lesh, 2012; National Council of Teachers of Mathematics [NCTM], 2000; National Governors Association Center for Best Practices [NGA Center] \& Council of Chief State School Officers [CCSSO]; Pollak, 2011). Engaging students in mathematical modeling experiences offers opportunities for interpretation and argumentation that are rare in most traditional word problems used in school mathematics (English \& Watters, 2004). Mathematical modeling has gained increased focus in assessments for school mathematics - both nationally and internationally (Organisation for Economic Co-operation and Development [OECD], 2003; Partnership for Assessment of Readiness for College and Careers [PARCC], 2014). However, the successful implementation of mathematical modeling remains a challenge for most teachers (English, 2009; Warwick, 2007).

One underlying reason for this challenge is that mathematical modeling usually requires both teachers and students to make sense of 
complex systems within an interdisciplinary context (Blum \& Borromeo Ferri, 2009; English, 2009). This requires teachers to redefine their roles - a balance of responsibility that is not evident in most U.S. mathematics classrooms (Blum \& Borromeo Ferri, 2009; Lesh 2012). Teachers need to create an environment that will foster mathematical modeling pedagogical practices that focus on student-centered classroom discourse and critical thinking. In order for teachers of mathematics to develop students' competencies, it is essential they gain strong knowledge of mathematical modeling and its process.

It is also important to have quantitative scales that allow generalizability to educational practice. The development of a scale provides researchers with a quantitative tool that is woefully lacking in the literature (Ziebarth, Fonger, \& Krathy, 2014). Currently, most researchers experience difficulty with determining whether an instrument is suitable for a particular study, and whether it will generate valid and reliable data for analyses (Hill \& Shih, 2009). According to Newcomer (2012), instruments with a clearly defined purpose and validity evidence are fundamental to conducting high quality large-scale quantitative studies. Therefore, it is imperative in developing a mathematical modeling knowledge scale (MMKS) to also investigate teachers' knowledge on the nature of mathematical modeling.

The purpose of this study was to address the challenges associated with developing tools to enhance quantitative research in mathematical modeling. The practice of modeling is consistent with the Common Core State Standard of mathematical practice-model with mathematics, and echoes the effective teaching practices and productive dispositions as explained in NCTM's principles to action (NCTM, 2014). In assessing teachers' knowledge of the nature of mathematical modeling through a scale development process, the following research questions were examined:

Research question 1: Do the scale items (MMKS) provide reliable and valid evidence about teachers' knowledge of the nature of mathematical modeling?

Research question 2: Does gender play a significant role in the differences between teachers' knowledge of the nature of mathematical modeling?

Research question 3: How do teachers conceptualize the nature of mathematical modeling?

\section{Theoretical Background}

\section{Mathematical Modeling}

During the past few decades, topics that have been central to mathematics education concerned the relationships between mathematics and the real world. Thus, mathematical modeling is not new in mathematics education. The phrase mathematical modeling is used to denote any relations whatsoever between mathematics and the real world (Blum \& Borromeo 
Ferri, 2009). Mathematical modeling is more than simply presenting students with traditional word problems. Rather, Lesh (2012) explained that mathematical modeling emphasizes conceptual understanding of big ideas in mathematics by describing or explaining things quantitatively, geometrically, or algebraically using models.

There are two main perspectives about the use of mathematical modeling in the teaching and learning of mathematics: (a) mathematical modeling as a distinct content area and (b) mathematical modeling as a tool to teach mathematics (Blum, 2015; Lesh, 2012). The research that perceives mathematical modeling as a distinct content area focuses on the modeling process, phases in the modeling process, and modeling abilities and competencies (Blum, 2015; Blum \& Borromeo Ferri, 2009; Borromeo Ferri, 2006). Alternatively, the research that identifies mathematical modeling as a tool to teach mathematics considers mathematical modeling activities as productive problem solving situations for teaching mathematics in meaningful ways (Lesh, 2012). In this study, mathematical modeling is defined as the process of translating between the real world and mathematics in both directions using the modeling process (Blum \& Borromeo Ferri, 2009). This definition embodies both perspectives of modeling in the teaching and learning of mathematics.

A popular idea about mathematical modeling among most $\mathrm{K}-12$ teachers concerns the use of representations to model a mathematical concept. This idea originates from teachers' understanding of NCTM's (2000) representation standard: students should be enabled to "use representations to model and interpret physical, social, and mathematical phenomena" (p. 67) and the Common Core State Standards, fourth standard of mathematical practice-model with mathematics (NGA Center \& CCSSO, 2010). However, students' use of representations during a modeling task is not sufficient to label their actions as mathematical modeling. Mathematical modeling includes (a) an understanding of the modeling process and (b) an interpretation of the mathematical model in a real-world context.

Mathematical modeling provides much more "powerful and effective ways to help students become (a) better problem solvers, and (b) better able to use mathematics in real-life situations beyond school" (Lesh, 2012, p. 197). Studies have shown that mathematical modeling supports and motivates students' interest in mathematics (English \& Watters, 2004; Pollak 2003). Additionally, when students are provided opportunities to engage in modeling tasks, their engagement reflects improvement in their mathematics achievements (Boaler, 2001). Recently, mathematical modeling literacy has increased in importance regarding mathematics and the world around us (NCTM, 2009, 2014; NGA Center \& CCSSO, 2010; OECD, 2003). Therefore, it was imperative to explore teachers of mathematics knowledge of the nature of mathematical modeling. 


\section{Teachers' Knowledge of Mathematical Modeling}

Most $\mathrm{K}-12$ teachers of mathematics have misconceptions about mathematical modeling and the modeling process (Gould, 2013; Spandaw \& Zwaneveld, 2010; Wolfe, 2013) due to their lack of knowledge about mathematical modeling (Blum, 2015). Additionally, most teachers may have had limited exposure to mathematical modeling and have unclear ideas of what is meant by the term mathematical modeling. Teachers also appear to know less about mathematical processes, tasks, pedagogies, and assessments associated with mathematical modeling (Blum, 2015; Gaston \& Lawrence, 2015).

Shulman (1986) emphasized the importance of teacher's content knowledge as a central aspect of teachers' professional competence. Twentytwo years later, Ball, Thames, and Phelps (2008) explained that teachers of mathematics need certain knowledge domains to teach mathematics effectively, because their knowledge affects student learning. Additionally, teacher education has been criticized in the area of teachers' mathematics content knowledge and in particular, mathematical modeling, for some time without its effectiveness being analyzed empirically (Kaiser, Schwarz, \& Tiedmann, 2010). Equally, there is increasing evidence about $\mathrm{K}-12$ teachers' limited knowledge of mathematical modeling (Blum \& Borromeo Ferri, 2009; Spandaw \& Zwaneveld, 2010).

Quantitative instruments for measuring teachers' knowledge of mathematical modeling are absent in most mathematics education journals. This contributes to the problem for most educators and researchers in determining whether an instrument is suitable for studies related to mathematical modeling, and whether such instruments generate reliable and valid data for analyses (Hill \& Shih, 2009). Additionally, instrument validity and reliability related to mathematical modeling as a mathematics education topic is also woefully lacking (Kaiser, Schwarz, \& Tiedmann, 2010). Although content knowledge is important for improving teaching and learning, attention to teachers' mathematical modeling knowledge has been uneven.

One can only teach what he or she knows, therefore, "teachers must have an in-depth knowledge not only of the specific mathematics they teach, but also of the mathematics that their students are to learn for the future" (Fennema \& Franke, 1992, p. 147). Anecdotal experiences indicate that most teachers are applying the same pedagogies and methodologies they experienced during their training in the classroom. NCTM's standards (NCTM, 2000, 2009, 2014) and the Common Core State Standards (NGA Center \& CCSSO, 2010) require teachers to develop new knowledge, pedagogies, and practices on mathematical modeling to increase students' mathematical achievement. 


\section{Methodology}

\section{Site and Participants}

This study was conducted with K-12 teachers of mathematics in 2015. With this research in mind, the researcher began to design a survey research as described by DeVellis (2012) and Fowler (2014). Specifically, a descriptive survey design (cross-sectional) was used for this study. K-12 teachers of mathematics in a Midwestern state self-selected to participate for a total of 71 teacher participants. Descriptive demographic data was collected on 62 teachers, because not all of the participants responded to the demographic questions. Of these 62 teachers, $77 \%$ of respondents were 35 years or older and almost $60 \%$ of the sample were identified as White or Caucasian. The respondents included 36 grades $\mathrm{K}-5$ teachers, nine grades $6-8$ teachers, and 17 grades 9-12 teachers of mathematics. Teaching experiences ranged from one year to 32 years and $85 \%$ of the sample self-identified as female, and $15 \%$ as male.

\section{Instrument}

Based on the analysis of several sources such as the Common Core State Standards, NCTM standards, and research articles (Blum \& Borromeo Ferri, 2009; DeVellis, 2012; Fowler, 2014; Gould, 2013; Lesh, 2012; NCTM 2000, 2009; NGA \& Center, 2010; Pollak, 2003, 2011; Wolfe, 2013), an initial mathematical modeling knowledge scale (MMKS) was developed with 22 items; formats included true or false items, multiple choice questions, and an open-ended question. The items were written in an objective-test format based on relevant literature and research on mathematical modeling. Using cognitive interviews, reviews with content experts and practicing teachers, as well as item analysis and factor analysis, the initial 22 items on the scale were modified and honed to a 13-item scale. The content experts and cognitive interviewers provided inputs as to the relevancy, adequacy, accuracy, and wording of items to establish content validity of the scale. The final online 13item scale survey included 12 true or false items and one open-ended question. Appendix A illustrates some of the scale items used during the study.

Additionally, respondents' responses to the open-ended question were categorized and rated as excellent, good, fair, and poor by two mathematics educators and the researcher. The raters are in the field of mathematics and mathematics education and their ratings were based on the definition of mathematical modeling exemplified in the rubric provided in Table 1. Because teachers' responses were typed there was no ambiguity about their responses, their statements were clear and straightforward. The ratings were coded as $4=$ excellent, $3=$ good, $2=$ fair, and $1=$ poor. The inter-rater reliability based on the intra-class correlation (ICC) was calculated to be .86 for single measures and .95 for average measures. The resulting ICC values 
were in the good to excellent range (Cicchetti, 1994), indicating that raters had a high degree of agreement.

\section{Data Collection and Analysis}

Because of the nature of the study, purposeful sampling was employed to identify the participants who responded to the online survey. The specific form of data collection was an online self-administered survey (Creswell, 2009). Invitation to take part in the electronic survey were sent out to potential respondents via Qulatrics - an online survey software. Their responses were downloaded and coded for statistical analyses. Survey data were only acceptable to the degree to which they were reliable and valid (DeVellis, 2012; Fowler, 2014). Therefore, the main goal of the data analyses was to have a reliable and valid scale that measured teachers of mathematics knowledge of the nature of mathematical modeling.

\section{Table 1}

\section{A Rubric for Evaluating the Definition of Mathematical Modeling}

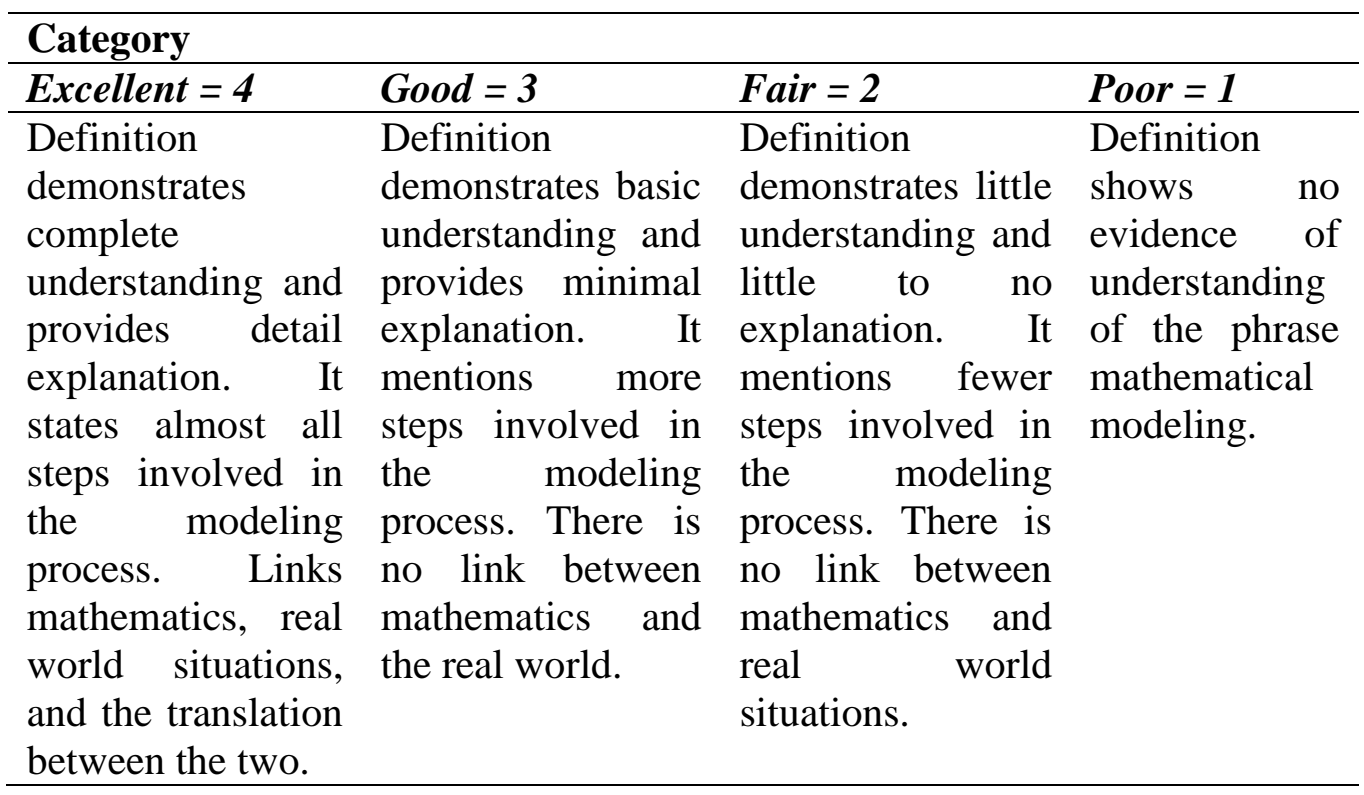

Data for the study were analyzed both quantitatively and qualitatively. The statistical procedures used to demonstrate the reliability and construct validity of the scale included univariate analysis, Cronbach's alpha reliability analysis, and exploratory factor analysis (EFA). Researchers have recommended different ratios and sample sizes when conducting EFA (e.g., Costello \& Osborne, 2005). However, the sample size of 71 for this pilot study was deemed appropriate because a sample size between 15 and 75 is considered adequate for pilot studies (Converse \& Presser, 1986; Johanson \& Brooks, 2010). Moreover, EFA is needed as part of any initial scale 
development to explore a potential factor structure and support the internal consistency of the items.

In this study, Cronbach's alpha was utilized to measure the internal consistency reliability of the scale. The reliability and factor analysis of the MMKS scores were based on the 12-item true or false questions. Thus, the total possible score on the MMKS was 12. Items answered correctly on the MMKS were coded a score of "1," and items answered incorrectly were coded a score of " 0. ." In addition, an independent $t$-test was performed to identify significant differences between teacher's gender and knowledge of the nature of mathematical modeling. The SPSS statistical software was used for all the analyses. All analyses were considered statistically significant with $p<.05$.

\section{Results and Discussion}

This study answered three main research questions by (a) providing reliable and valid evidence to support items on the MMKS, (b) exploring the influence of the demographic variable gender on teachers' knowledge of the nature of mathematical modeling, and (c) examining how teachers' conceptualize the nature of mathematical modeling. Research question 1 sought to provide reliable and valid evidence to support the development of the scale to determine teachers' knowledge of the nature of mathematical modeling.

Cronbach's coefficient of internal consistency and exploratory factor analysis (EFA) were used to answer this research question. Cronbach's coefficient alpha was used to calculate the reliability of the MMKS scores. The correlation matrix between items and the item-total correlations were examined to determine item reliability. Although three of the 12 items on the MMKS had item-total correlations less than .30, all 12 items were retained in the analysis because of their correlations $(\mathrm{r} \geq .25)$ and theoretical relevance (Nunnally \& Bernstein, 1994; Osterlind, 2010). The overall internal consistency reliability of the MMKS for this sample was .80 , indicating a good reliable scale (DeVellis, 2012; Fowler, 2014). Table 2 provides information on the item-total correlations and alpha values if an item was deleted on the MMKS.

In assessing the internal structure of the items on the MMKS, exploratory factor analysis was used to find out about the interrelationships among the items, which also provided validity evidence. The Kaiser-MeyerOlkin (KMO) measure of sampling adequacy of .70 was acceptable and support factor analysis (Osterlind, 2010). Additionally, Bartlett's test was statistically significant $(p<.001)$ and the rule of subjects-to-variable ratio of no lower than five was satisfied (Bryant \& Yarnold, 1995); therefore, common factor analysis was appropriate for the data.

A principal axis factoring (PAF) with a varimax rotation was conducted on the 12 items. Varimax rotation was used to make interpretation 
of the retained unidimensional factor. Examination of the factor loadings and extracting only one factor based on theoretical relevance to interpret the items explained about $29 \%$ of the shared variance on the MMKS for this sample. All the factor loading values were greater than .30 , indicating the items correlated well with the whole scale. Thus, using one factor to interpret all the 12 items seems strongest statistically and most interpretable. The single factor extracted on the MMKS was labeled knowledge of modeling.

Table 2

Item-Total Correlations of all the 12 Items on the MMKS

\begin{tabular}{lccccc}
\hline Items & $M$ & $S D$ & $S E$ & ITC & $\alpha$-if item deleted \\
\hline Item 1 & .92 & 0.28 & .03 & .27 & .80 \\
Item 2 & .90 & 0.30 & .04 & .59 & .77 \\
Item 3 & .80 & 0.40 & .05 & .48 & .78 \\
Item 4 & .72 & 0.45 & .05 & .28 & .80 \\
Item 5 & .86 & 0.35 & .04 & .43 & .79 \\
Item 6 & .86 & 0.35 & .04 & .54 & .78 \\
Item 7 & .77 & 0.42 & .05 & .27 & .80 \\
Item 8 & .90 & 0.30 & .04 & .44 & .79 \\
Item 9 & .82 & 0.39 & .05 & .63 & .77 \\
Item 10 & .94 & 0.23 & .03 & .39 & .79 \\
Item 11 & .93 & 0.26 & .03 & .31 & .80 \\
Item 12 & .77 & 0.42 & .05 & .69 & .76 \\
\hline Note: $N=71 ;$ ITC = item-total correlation. & &
\end{tabular}

Research question 2 explored whether there was a significant difference in teachers' knowledge of mathematical modeling based on their gender. The overall total mean score on the MMKS was $10.20(S D=2.34)$, indicated the teachers had a satisfactory knowledge of the nature of mathematical modeling. An independent $t$-test was performed on the variable gender to explore whether there were any differences between male and female teachers' as observed with other knowledge constructs (Rowan, Schilling, Ball, \& Miller, 2001).

All the assumptions for conducting an independent $t$-test were tenable, however, Levene's test indicated unequal variances $(F=5.26, p=.018)$. The independent sample $t$-test indicated that the mean scores on the scale were statistically significant for female teachers $(M=10.42, S D=2.13)$ and for male teachers $(M=8.89, S D=3.14), t(60)=2.07, p<.05$, with a standardized effect size $d=.58$. The findings show that female $\mathrm{K}-12$ teachers did have a 
relatively higher knowledge of mathematical modeling than their male counterparts.

Research question 3 was analyzed qualitatively and quantitatively. This was achieved by asking teachers to express their thoughts or describe exactly mathematical modeling through an open-ended item on the survey. Specifically, respondents were asked to write a brief definition for the phrase mathematical modeling. A total of 54 teachers responded to this open-ended item. There were notable findings in examining teachers' responses on their knowledge or understanding about the phrase mathematical modeling based on the rubric provided in Table 1 . Of the 54 teachers who responded to this question, only four $(7 \%)$ of the responses could be categorized as excellent responses. Thirty-three $(61 \%)$ of the teachers had misconceptions about mathematical modeling and they confused mathematical modeling with model mathematics. Appendix B illustrates some of the sample responses from the respondents. Figure 1 provides the distribution of respondents' responses about the meaning of the phrase mathematical modeling.

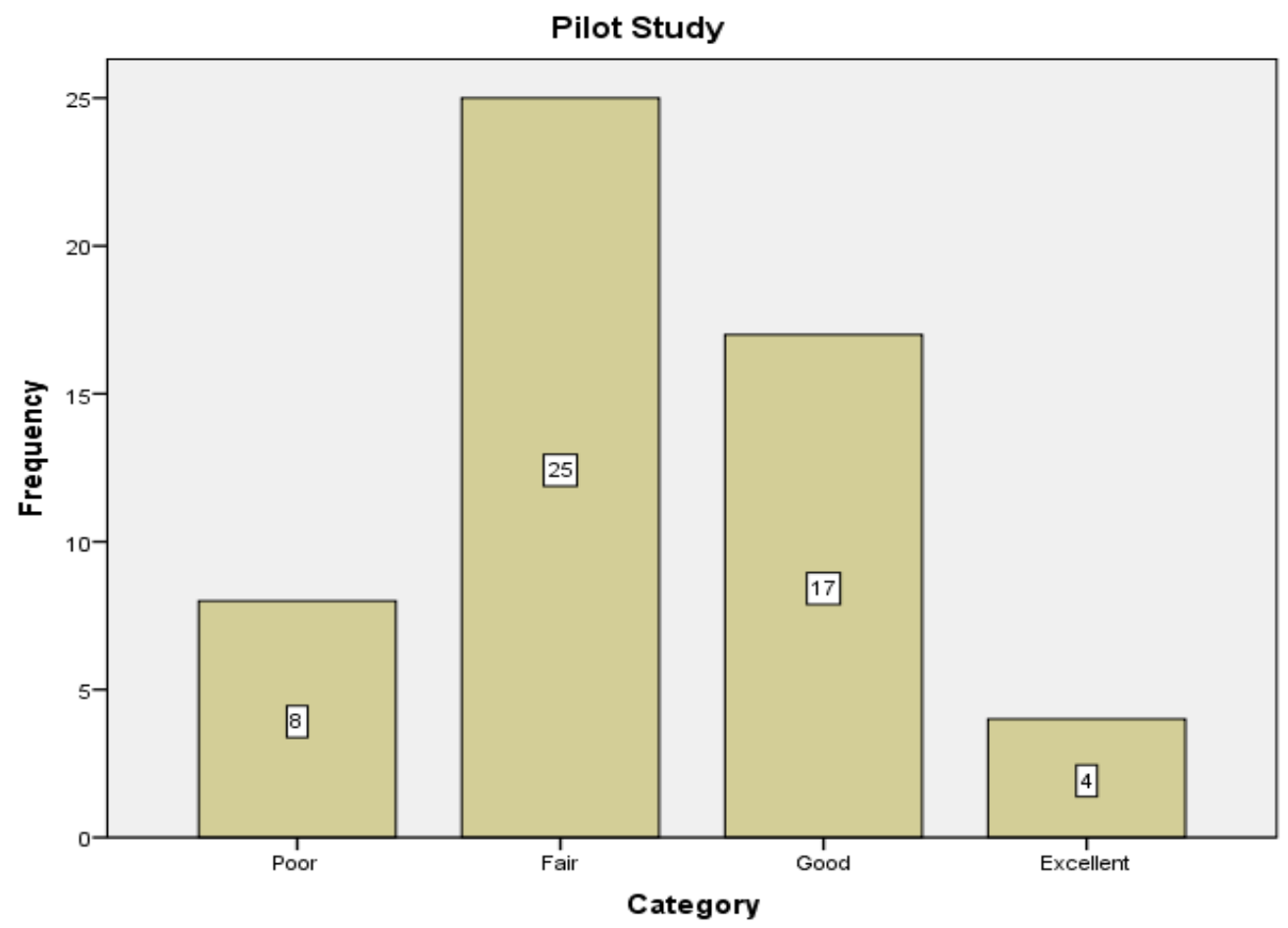

Figure 1. A bar chart showing teachers' responses about the phrase mathematical modeling.

Again, 33(61\%) of the teachers' explanation or definition incorrectly assumed mathematical modeling as using physical objects, manipulatives, or representations to solve mathematics problem. Experiences shared by the respondents indicated the phrases mathematical modeling and the modeling 
process were new terms to most of the teachers, and they had little or no experience with mathematical modeling practices. Most of their explanations failed to recognize mathematical modeling as a translation between mathematics and the real world, and that it is an iterative process that involves choices and assumptions by the modeler.

\section{Conclusion and Implications}

This exploratory study was designed to develop and examine the psychometric properties of the MMKS among a developmentally appropriate sample. Overall, the findings from this study suggest quantitative instruments appear to be helpful for measuring and understanding teachers' knowledge of mathematical modeling. The items on the MMKS were found to yield reliable and valid data for measuring teachers' knowledge of the nature of mathematical modeling. Moreover the MMKS generated a single score representing individual teacher's knowledge of the nature of mathematical modeling.

Although the KMO statistics indicated the sample was adequate at .70 for common factor analysis (Osterlind, 2010), some limitations were evident with this study and if addressed can improve the design of future studies. Having a larger sample and using confirmatory factor analysis in future studies, might result in a more robust factor analysis. Moreover, it is probable that social desirability - a tendency to respond in a manner that will be viewed favorably by others (Tourangeau, Rips, \& Rasinski, 2000) - may have contributed in how the respondents reacted or responded to the scale items. Because of the above limitations, results from this pilot study have to be taken and interpreted with caution when generalizing to a larger population.

Nevertheless, great attention was given to having the items generated and examined by content and subject matter experts, and then exploring a potential factor structure for the scale to provide a solid methodological process to support the data results. Thus, this pilot study used a rigorous approach to demonstrate that the initial MMKS is a promising quantitative tool for advancing research on teachers' knowledge of mathematical modeling. Results from this pilot study revealed that participants had a satisfactory knowledge of the nature of mathematical modeling. However, responses on the open-ended question indicated that $61 \%$ of the teachers had misconceptions about the phrase mathematical modeling as shown in Figure 1. The reliability and validity evidence provided, as well as the psychometric properties of the initial MMKS demonstrates its potential in mathematics education research. Therefore, the initial MMKS has promising psychometric properties across different sociodemographic subgroups, making it appropriate for research in diverse populations.

A shift in teachers' knowledge of mathematical modeling will help students do mathematics as set forth by the standards in the CCSSM and 
NCTM. Thus, having a scale that measures teachers' knowledge of teaching mathematical modeling will benefit professional development and teacher preparation. The development of the initial MMKS is a step in the right direction to achieve this goal. Teachers' professional competence on mathematical modeling will enhance the teaching and learning of mathematics. Results from this study and other published materials (e.g., Kaiser, Schwarz, \& Tiedmann, 2010; Spandaw \& Zwaneveld, 2010) also indicate a need exists for modeling training standards or courses to be integrated in teacher preparation programs for teachers of mathematics. Finally, the psychometric results suggest the scale is suitable for a variety of settings related to mathematical modeling education. The results also indicate the initial MMKS stands to benefit mathematics educators, researchers, teachers, and advance mathematical modeling education.

\section{References}

Ball, D. L., Thames, M. H., \& Phelps, G. (2008). Content knowledge for teaching: What makes it special? Journal of Teacher Education, 59, 389-407.

Blum, W. (2015). Quality teaching of mathematical modelling: What do we know, what can we do? In S. J. Cho (Ed.), Proceedings of the 12th International Congress on Mathematical Education: Intellectual and attitudinal challenges (pp. 73-96). New York, NY: Springer. doi:10.1007/978-3-319-12688-3_9

Blum, W., \& Borromeo Ferri, R. (2009). Mathematical modelling: Can it be taught and learnt? Journal of Mathematical Modelling and Application, 1, 45-58.

Boaler, J. (2001). Mathematical modelling and new theories of learning. Teaching Mathematics \& Its Applications, 20, 121-127.

Borromeo Ferri, R. (2006). Theoretical and empirical differentiations of phases in the modelling process. ZDM, 38(2), 86-95. doi:10.1007/BF02655883

Bryant, F. B., \& Yarnold, P. R. (1995). Principal components analysis and exploratory and confirmatory factor analysis. In L. G. Grimm \& R. R. Yarnold (Eds.), Reading and understanding multivariale statistics (pp. 99-136). Washington, DC: American Psychological Association.

Cicchetti, D. V. (1994). Guidelines, criteria, and rules of thumb for evaluating normed and standardized assessment instruments in psychology. Psychological Assessment, 6, 284-290. doi:10.1037/10403590.6.4.284

Converse, J. M., \& Presser, S. (1986). Survey questions: Handcrafting the standardized questionnaire. Beverly Hills, CA: Sage. 
Costello, A. B., \& Osborne, J. W. (2005). Best practices in exploratory factor analysis: Four recommendations for getting the most from your analysis. Practical Assessment, Research \& Evaluation, 10, 1-9.

Creswell, J. W. (2009). Research design: Qualitative, quantitative, and mixed methods approaches. (3rd ed.). Thousand Oaks, CA: Sage.

DeVellis, R. F. (2012). Scale development: Theory and applications. (3rd ed.). Los Angeles, CA: Sage.

English, L. (2009). Promoting interdisciplinarity through mathematical modelling. ZDM, 41, 161-181. doi:10.1007/s11858-008-0106-z

English, L. D., \& Watters, J. J. (2004). Mathematical modelling with young children. In J. M. Hoines \& B. A. Fuglestad (Eds.), Proceedings of the 28th International PME Conference (pp. 335-342). Bergen, Norway: Bergen University College.

Fennema, E., \& Franke, M. L. (1992). Teachers' knowledge and its impact. In D. A. Grouws (Ed.), Handbook of research on mathematics teaching and learning (pp. 147-164). New York, NY: Macmillan.

Fowler, F. J. (2014). Survey research methods (5th ed.) Thousand Oaks, CA: Sage.

Gaston, J. L., \& Lawrence, B. A. (2015). Supporting teachers' learning about mathematical modeling. Journal of Mathematics Research, 7(4), 1-11. doi:10.5539/jmr.v7n4p1

Gould, H. T. (2013). Teachers' conceptions of mathematical modeling.

Retrieved from http://academiccommons.columbia.edu/ item/ac: 161497

Hill, H. C., \& Shih, J. C. (2009). Examining the quality of statistical mathematics education research. Journal for Research in Mathematics Education, 40(3), 241-250.

Johanson, G. A., \& Brooks, G. P. (2010). Initial scale development: sample size for pilot studies. Educational and Psychological Measurement, 70(3), 394-400.

Kaiser, G., Schwarz, B., \& Tiedemann, S. (2010). Future teachers' professional knowledge on modeling. In R. Lesh, P. L. Galbraith, C. R. Haines, \& A. Hurford, (Eds.), Modeling students' mathematical modeling competencies. ICTMA 13 (pp. 433-444). New York, NY: Springer. doi:10.1007/978-1-4419-0561-1_37

Lesh, R (2012). Research on models \& modeling and implications for common core state curriculum standards. In R. Mayes, L. Hatfield, \& S. Belbase, (Eds.), WISDOM Monograph: Quantitative reasoning and mathematical modeling: A driver for STEM integrated education and teaching in context, (Vol. 2, pp. 197-203), Laramie, WY: University of Wyoming.

National Council of Teachers of Mathematics (2000). Principles and standards for school mathematics. Reston, VA: Author. 
National Council of Teachers of Mathematics (2009). Focus in high school mathematics: Reasoning and sense making. Reston, VA: Author.

National Council of Teachers of Mathematics. (2014). Principles to actions: Ensuring mathematical success for all. Reston, VA: Author.

National Governors Association Center for Best Practices \& Council of Chief State School Officers. (2010). Common core state standards for mathematics. Washington, DC: Author. Retrieved from http://core standards.org/assets/CCSSI_Math\%20Standards.pdf

Newcomer, K. (2012). Basics of design for evaluation of cohesion policy interventions. In K. Olejniczak, M. Kozak \& B. Bienias (Eds.), Evaluating the effects of regional interventions: A look beyond current structural funds practice. Republic of Poland: Ministry of Regional Development.

Nunnally, J. C., \& Bernstein, I. H. (1994). Psychometric theory (3rd ed.). New York, NY: McGraw-Hill.

Organisation for Economic Co-operation and Development (2003). The PISA 2003 assessment framework-mathematics, reading, science and problem solving, Knowledge and Skills. Paris, France: OECD Press.

Osterlind, S. J. (2010). Modern measurement: Theory, principles, and applications of mental appraisal. Upper Saddle River, NJ: Pearson.

Partnership for Assessment of Readiness for College and Careers. (2014). The PARCC assessment. Retrieved from http://www.parcconline.org/ parcc-assessment

Pollak, H. O. (2003). A history of the teaching of modelling. In G. M. A. Stanic \& J. Kilpatrick (Eds.), A history of school mathematics, (pp. 647-671). Reston, VA: National Council of Teachers of Mathematics.

Pollak, H. O. (2011). What is mathematical modeling? Journal of Mathematics Education at Teachers College, 2, 64.

Rowan, B., Schilling, S. G., Ball, D. L., \& Miller, R. (2001). Measuring teachers' pedagogical content knowledge in surveys: An exploratory study. Retrieved from http://www.sii.soe.umich.edu/documents/pck\% 20final\%20report\%20revised\%20BR100901.pdf

Shulman, L. S. (1986). Those who understand: Knowledge growth in teaching. Educational Researcher, 15(2), 4-14.

Spandaw, J., \& Zwaneveld, B. (2010). Modelling in mathematics' teachers' professional development. Paper presented at the Proceedings of the sixth Congress of the European Society for Research in Mathematics Education -Working group 11, (p. 2076-2085), Lyon, France: INRP.

Tourangeau, R., Rips, L. J., \& Rasinski, K. (2000). The psychology of survey response. New York, NY: Cambridge University Press.

Warwick, J. (2007). Some reflections on the teaching of mathematical modeling. The Mathematics Educator, 17(1), 32-41.

Wolfe, N. B. (2013). Teachers' understanding of and concerns about mathematical modeling in the common core standards (Doctoral 
dissertation). Retrieved from http://search.proquest .com.proxy.library. ohiou.edu/docview/1432193702? accountid=12954

Ziebarth, S., Fonger, N., \& Kratky, J. (2014). Instruments for studying the enacted mathematics curriculum. In D. Thompson, \& Z. Usiskin (Eds.), Enacted mathematics curriculum: A conceptual framework and needs (pp. 97-120). Charlotte, NC: Information Age Publishing.

\section{Appendix A \\ Mathematical Modeling Knowledge Scale (MMKS)}

SECTION 1: This section focuses on knowledge about the nature of mathematical modeling. Consider how they can be used in the classroom. The items below describe the nature of mathematical modeling. Please respond to these items to the best of your ability.

Q1. The practice of mathematical modeling involves a single-step process.

O True

O False

Q3. The mathematical modeling process is the same as mathematical problemsolving process.

O True

F False

Q5. Mathematical modeling involves problem posing before problem solving.

O True

False

Q7. Solving mathematical modeling tasks always require the use of technology.

O True

O False

Q10. Mathematical modeling tasks are of low cognitive demand.

O True

O False

Q13. Write a brief definition of mathematical modeling.

SECTION 2: Demographic Information and Experience with Mathematical Modeling. This section seeks information about you and your experience with mathematical modeling.

Q14. What is your gender?

O Male

F Female

O Other

Q15. What is your age in years?

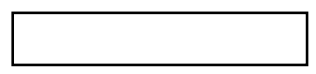


Q16. Which of the following best describes your race and ethnicity?

O White or Caucasian

O Black or African American

O American Indian or Alaska Native

O Asian or Asian American

O Native Hawaiian or Pacific Islander

O Hispanic or Latino

O Other

Q19. In which grade level(s) do you teach?

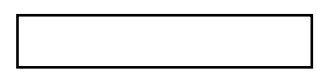

Q20. What is your highest degree earned?

O Associate's

O Bachelor's

O Master's

O Master's +30

O Doctorate

Q23. Do you teach mathematical modeling activities?

$\mathrm{O}$ Yes

O No

O Not sure

Q27. Please comment on your experiences with mathematical modeling.

\section{Appendix B}

Selected sample responses of participants to the open-ended question. The responses were categorized into excellent (E), Good (G), Fair (F), and Poor (P) based on the rubric. The responses were coded using anonymous identifiers. For example.

$\mathrm{E} 1=$ represents sample 1 of the excellent responses;

$\mathrm{G} 2$ = represents sample 2 of the good responses;

$\mathrm{F} 3=$ represent sample 3 of the fair responses; and

$\mathrm{P} 2=$ represents sample 2 of the poor responses.

Excellent $(\mathrm{E})$ responses.

E1: Mathematical modeling involves having the students apply the math that they know to the problems and to their everyday life. It also involves them changing the model as different needs arise or as they realize that they need to make improvements. It helps them come up with new assumptions and realizations.

E2: Mathematical modeling is about taking a real world problem, applying mathematical strategies to solve the problem and then relating the solution back to the real world.

E3: My definition of mathematical modeling is students are given a problem to solve they will use their knowledge to make a visual representation of the math and will be able to explain it and then relate the problem to something in a real world situation. 


\section{Good responses.}

G1: Mathematical modeling takes concepts and procedures learned in mathematics classes, and make those processes function in an application type setting.

G2: Mathematical modeling is a process in which students are challenged with a problem or problems and then taken through the thinking process in order to give gradual release of thinking. It allows for more quality thinking rather than cut and dry answers.

G3: Mathematical modeling is analyzing a situation, posing a question/problem, expressing the known variables in different forms (using different entry points until a path to the solution presents itself), using mathematics, logic, technology to known and unknown quantities and their

Fair (F) responses. relationships, reach a solution.

F1: A mathematic model is when you are making an activity, cognitively, where you think about how an object or device behaves. It is done for fun to show students how to formulate and problem solve.

F2: Mathematical modeling is guiding students through the problem solving process. The use of drawn or figure manipulation to explain the mathematical process or thinking to solve a problem.

F3: Using pictures, words, and numbers to explain a mathematical problem. Working collaboratively to explain thinking on a problem.

Poor (P) responses:

P1: Mathematical modeling is about giving examples first.

P2: Showing your work with numbers, words, or pictures to others.

P3: Math modeling is when an instructor models the correct way or ways to solve a problem.

\section{Author:}

Reuben S. Asempapa

Penn State Harrisburg, Middletown, PA

Email: rsa26@psu.edu 